\title{
Integrated Learning System
}

National Cancer Institute

\section{Source}

National Cancer Institute. Integrated Learning System. NCI Thesaurus. Code C19544.

A computer system that provides tutorial instruction in academic subjects at an individual level in a format that allows students to master material at their own pace, i.e., CME courses. 